\title{
Relationship between Handgrip Strength and Low-grade Inflammation in Older Adults with Depression
}

\author{
Kwi Young Kang ${ }^{1,2}$, Young-Eun Jung ${ }^{3}$, Hwan Jang, Moon-Doo Kim³, Won-Myong Bahk ${ }^{4}$ \\ ${ }^{1}$ Department of Internal Medicine, College of Medicine, The Catholic University of Korea, Seoul, 'Division of Rheumatology, Department of \\ Internal Medicine, Incheon St. Mary's Hospital, College of Medicine, The Catholic University of Korea, Incheon, ${ }^{3}$ Department of Psychiatry, \\ College of Medicine, Jeju National University, Jeju, ${ }^{4}$ Department of Psychiatry, College of Medicine, The Catholic University of Korea, Seoul, \\ Korea
}

Objective: The relationship among physical functional decline, low-grade inflammation, and depression remains unclear. The aim of this study was to examine the association between hand grip strength (HGS) and high-sensitivity C-reactive protein (hs-CRP) in a large sample with depression.

Methods: This study used data obtained from a representative Korean sample of 9,402 people who participated in the seventh Korean National Health and Nutrition Examination Survey. Physical function was assessed using a digital grip strength dynamometer. Depression was identified using a cutoff of 5 on the Patient Health Questionnaire-9 (PHQ-9), and high hs-CPR level was defined as $\geq 3.0 \mathrm{mg} / \mathrm{L}$.

Results: In older adults ( $\geq 60$ years) with depression, $43.8 \%$ of those with high hs-CRP levels had low HGS, compared to $21.8 \%$ of those with hs-CRP levels $<3.0 \mathrm{mg} / \mathrm{L}(p=0.002)$. Multivariate analysis revealed that, after adjustments for potentially confounding factors, high hs-CRP was independently associated with lower HGS (B $=-2.25$; $95 \%$ confidence interval $=-4.49$ to -0.02 ) in older adults with depression, but not in younger or middle-aged adults with depression.

Conclusion: These findings suggest a significant correlation between physical functional decline and low-grade inflammation in older adults with depression.

KEY WORDS: Hand grip strength; C-reactive protein; PHQ-9; Depression; Inflammation; Older adults.

\section{INTRODUCTION}

Handgrip strength (HGS) serves as a simple, noninvasive proxy measure for physical functioning/performance $[1,2]$. Several studies have shown that low HGS, as an indicator of physical functional decline, predicts negative clinical outcomes such as functional impairment

Received: January 4, 2021 / Revised: January 14, 2021

Accepted: January 15, 2021

Address for correspondence: Young-Eun Jung

Department of Psychiatry, College of Medicine, Jeju National

University, 15 Aran 13-gil, Jeju 63241, Korea

E-mail: jyejye77@daum.net

ORCID: https://orcid.org/0000-0001-7608-0009

Won-Myong Bahk

Department of Psychiatry, Yeouido St. Mary's Hospital, College of Medicine, The Catholic University of Korea, 10 63-ro,

Yeongdeungpo-gu, Seoul 07345, Korea

E-mail: wmbahk@catholic.ac.kr

ORCID: https://orcid.org/0000-0002-0156-2510 and mortality in various populations of different ages $[3,4]$, although the mechanisms linking muscle strength and disease outcomes remain poorly understood. One current hypothesis is that inflammatory processes might explain the association between muscle strength and mortality. Previous studies have reported associations between muscle strength and inflammatory processes; unfavorable levels of inflammatory biomarkers, such as elevated C-reactive protein, are also linked with a physical functional decline and adverse health outcomes [5-8].

Recently, several reports have focused on the relationship between low HGS and depression. Previous crosssectional and longitudinal studies have shown associations between lower HGS and depressive symptoms [9-14]. However, the causal mechanisms underlying this relationship have not yet been determined. Inflammatory processes or age-associated changes in the immune sys-

(c) This is an Open-Access article distributed under the terms of the Creative Commons Attribution Non-Commercial License (http://creativecommons.org/licenses/by-nc/4.0) which permits unrestricted non-commercial use, distribution, and reproduction in any medium, provided the original work is properly cited. 
tem may underlie the link between low HGS and depression. Low-grade inflammation has been associated with depression and physical functional decline; the literature suggests that this relationship is likely bidirectional [15-17].

The purpose of this study was to examine the relationship between depression and physical functional decline, as evidenced by low HGS. The rate of low HGS was determined among adults with depression by using a representative sample of Korean adults stratified according to age group. In addition, this study examined whether high levels of high-sensitivity C-reactive protein (hs-CRP), an indicator of low-grade inflammation [18], were associated with low HGS in adults with depression, which elucidated potential links among hs-CRP, HGS, and age in adults with depression.

\section{METHODS}

\section{Study Participants}

The data for this study were extracted from the seventh Korea National Health and Nutrition Examination Survey (KNHANES VII, 2016-2018). The KNHANES has been conducted by the Ministry of Health and Welfare of the Korean Government since 1998 to assess the general health and nutritional statuses of Koreans. It is a 3-year cross-sectional study comprising health examinations, health surveys, and nutritional surveys that is administered to a representative sample of the entire Korean population, identified by means of a stratified cluster-sampling method. The data are collected through household interviews and standardized physical examinations conducted at mobile examination centers [19]. The KNHANES database is publicly available at the KNHANES website (http://knhanes.cdc.go.kr). All the protocols were approved by the Institutional Review Board of the Korean Centers for Disease Control and Prevention (2013-12EXP-03-5C).

The present study was based on participants in the first (2016) and third (2018) years of the seventh KNHANES. Notably, 2017 data were excluded in this study because the Patient Health Questionnaire-9 (PHQ-9) was not included in the survey items during that year. KNHANES VII-1 and VII-3 (2016 and 2018) examinations and health surveys were completed by 8,150 and 7,992 participants, respectively. The study's flow diagram is presented in Figure 1. The following individuals were included in this analysis: those aged $\geq 19$ years ( $n=12,875)$ who completed the PHQ-9 ( $n=11,085)$. Of the individuals with PHQ-9 data, only those with available serum hs-CRP data were eligible for inclusion ( $n=10,820)$. The following individuals were excluded: those who had been diagnosed with rheumatoid arthritis by a doctor $(n=215)$; those with limited physical activity ( $\mathrm{n}=797)$; and those who did not complete an assessment of HGS $(\mathrm{n}=406)$. The remaining 9,402 individuals (4,312 males and 5,090 females) were included in this study.

\section{Assessment and Evaluation}

\section{Depression}

The presence of depression was identified using the PHQ-9, a reliable and valid screening tool for measuring depression severity over the prior 2 weeks. The PHQ-9 is composed of nine items rated from 0 (not at all) to 3 (symptoms present nearly every day); the scores for each item are summed to produce a total depression severity score (range, 0-27) [20]. The Korean version of the PHQ-9 has high internal consistency (Cronbach's $\alpha=$ 0.86), and the optimal cut-off total score indicating the presence of depression is 5 . Thus, participants were con-

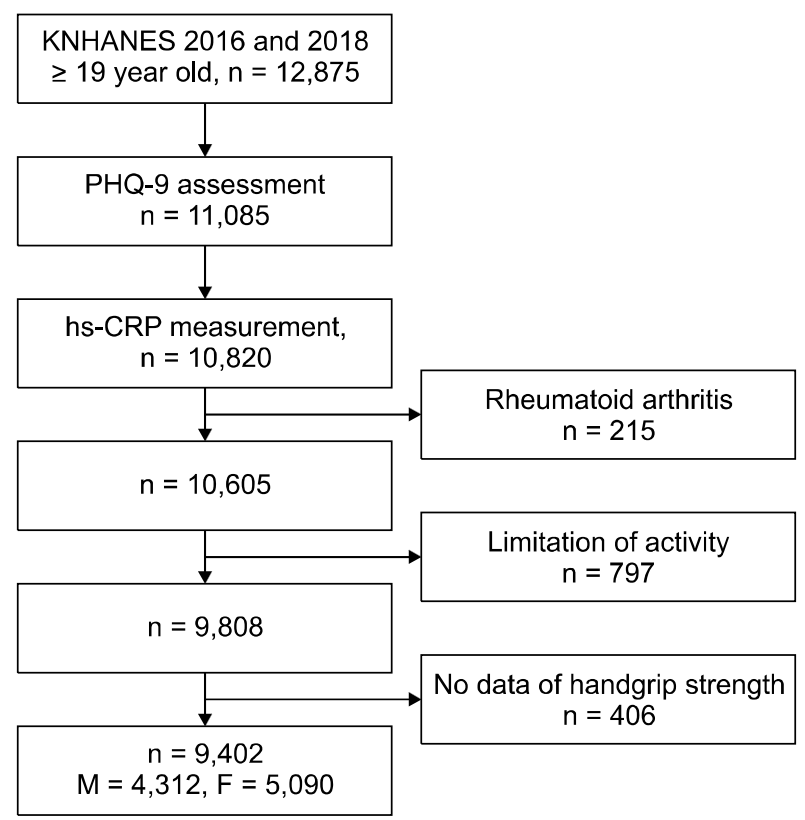

Fig. 1. Selection of study participants. KNHANES, Korea National Health and Nutrition Examination Survey; hs-CRP, high sensitivity C-reactive protein; PHQ-9, Patient Health Questionnaire-9. 
sidered to have depression if their total PHQ-9 score was $\geq 5[21]$.

\section{HGS}

HGS was measured using a digital grip strength dynamometer (TKK 5401 GRIPD; Takei, Niigata, Japan), which measures force between 5.0 and $100.0 \mathrm{~kg}$ and has an adjustable grip span. The minimum measurement unit is 0.1 kg. During the assessment, participants were asked to stand upright with their feet hip-width apart and to look straight ahead with their elbow fully extended. The dynamometer was held with the testing hand in a comfortable neutral position (not flexed or extended) with $90^{\circ}$ flexion at the index finger. Participants were instructed to squeeze the grip continuously with full force for at least 3 seconds. They were asked not to swing the grip dynamometer during the test and not to hold their breath. The time between trials was approximately 60 seconds. Each hand was tested three times; the highest reading from the dominant hand was used as maximum grip strength, expressed in $\mathrm{kg}$ [22]. Low HGS values were defined as $<26$ $\mathrm{kg}$ for males and $<18 \mathrm{~kg}$ for females [23].

\section{hs-CRP levels}

Blood samples were collected in 3-ml EDTA-coated tubes (BD Vacutainer, Franklin Lakes, NJ, USA). Serum samples used for the analysis of hs-CRP were stored at $2-$ $8^{\circ} \mathrm{C}$ in refrigerated containers after blood had been collected. All laboratory analyses were performed within 24 hours of sample collection. Serum hs-CRP levels were measured using an immunoturbidimetric apparatus (Cobas, Roche, Germany), which was calibrated daily with reference standards between 0.15 and $20.0 \mathrm{mg} / \mathrm{L}$. To compare the prevalences of depression among individuals with different levels of hs-CRP, an hs-CRP level of $3.0 \mathrm{mg} / \mathrm{L}$ was used. High hs-CRP was defined as $\geq 3.0 \mathrm{mg} / \mathrm{L}$, the cutoff stipulated by the American Heart Association and Centers for Disease Control and Prevention to indicate "high risk" for cardiovascular disorders [24].

\section{Study variables}

Age, sex, weight, height, smoking status, alcohol use problems, household income, physical activity, and protein intake were recorded. Weight and height were collected in accordance with standardized procedures; body mass index (BMI) was calculated as the weight in kilo- grams divided by the square of height in meters. In terms of smoking status, participants were categorized as current smokers or non-smokers. To obtain information regarding alcohol use problems, the Alcohol Use Disorder Identification Test-Alcohol Consumption instrument was administered. A cutoff score of 8 was used to indicate alcohol use problems in this study [25]. Household income was categorized in quartiles.

Physical activity was assessed using the International Physical Activity Questionnaire-short form, which estimates overall physical activity in metabolic equivalent of task (MET)-min/week by determining the duration (in minutes) and number of days (per week) of engagement in three specific types of activity (walking, moderate-intensity activity, and high-intensity activity) across a comprehensive set of domains (leisure time, work-related activity, transport-related physical activity, and domestic and gardening activity) in the prior 7 days [26]. The MET is a unit for estimation of the amount of oxygen used by the body during physical activity. Participants were classified into three physical activity levels (low, moderate, high) based on the cutoff total MET-min/week for each category [27]. Protein intake was assessed with a 24-hour dietary recall questionnaire administered by a trained dietitian. The results were generated using the Food Composition Table developed by the National Rural Resources Development Institute [28]. Inadequate protein intake was defined as protein intake below the recommended dietary reference intake for Koreans in 2015, according to the Korean Nutrition Society.

Participants were considered to have hypertension if they had systolic blood pressure $\geq 140 \mathrm{mmHg}$, diastolic blood pressure $\geq 90 \mathrm{mmHg}$, or if they were receiving treatment for hypertension. Participants were considered to have diabetes if they had a fasting blood glucose level $\geq 126 \mathrm{mg} / \mathrm{dl}$ that was first detected in this survey, used an antidiabetic medication, or had been previously diagnosed with diabetes by a doctor. Participants were considered to have dyslipidemia if they had total cholesterol level $\geq 240 \mathrm{mg} / \mathrm{dl}$ or if they were receiving treatment for dyslipidemia. The National Cholesterol Education Program-Adult Treatment Panel III criteria were used to determine whether metabolic syndrome was present; the cut-offs for the Asia-Pacific region were applied [29]. Participants were considered to have metabolic syndrome if three or more of the following criteria were met: (i) sys- 


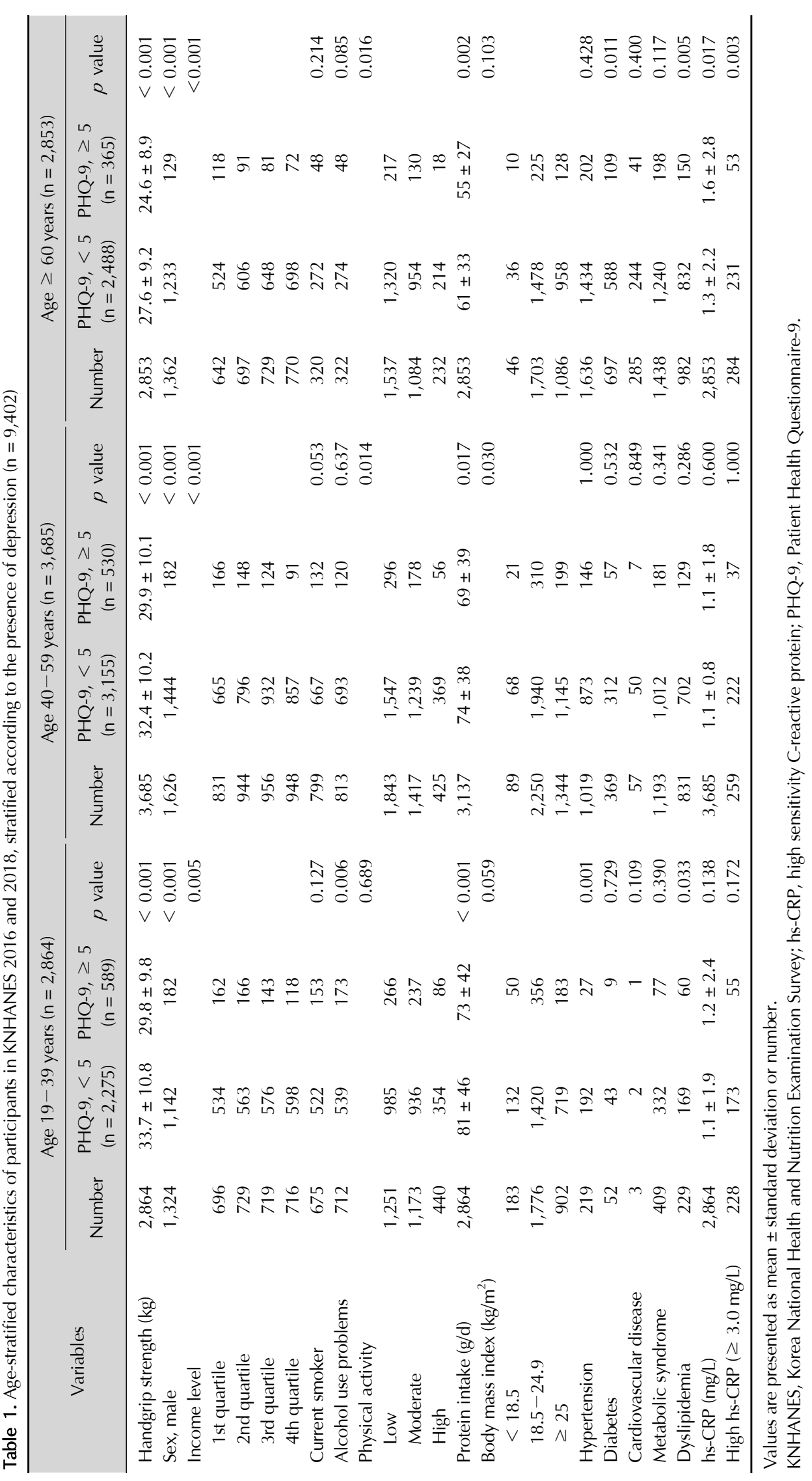


tolic/diastolic blood pressure $\geq 130 / 85 \mathrm{mmHg}$ or antihypertensive drug treatment; (ii) fasting serum triglyceride level $\geq 150 \mathrm{mg} / \mathrm{dl}$; (iii) low HDL-C level ( $<40 \mathrm{mg} / \mathrm{dl}$ in males and $50 \mathrm{mg} / \mathrm{dl}$ in females); (iv) waist circumference $\geq 90 \mathrm{~cm}$ in males and $\geq 80 \mathrm{~cm}$ in females; and (v) fasting serum glucose level $\geq 100 \mathrm{mg} / \mathrm{dl}$ or use of antidiabetic medication.

\section{Statistical Analysis}

Continuous data are expressed as mean (standard deviation [SD]); categorical data are expressed as percentages. Initial analyses explored differences in participant characteristics according to the presence of depression. The chi-square test was used for comparison of categorical variables; the $t$ test was used for comparison of continuous variables.

The association between serum hs-CRP levels and HGS was assessed using multivariate linear regression models with progressive levels of adjustment. In each of these models, the main independent variable was serum hs-CRP level ( $<3.0 \mathrm{mg} / \mathrm{L}$ vs. $\geq 3.0 \mathrm{mg} / \mathrm{L}$ ) and the dependent variable was HGS. Model 1 was adjusted for sex and age; model 2 included model 1, with additional adjustments for BMI and income; and model 3 included model 2, with additional adjustments for current smoking, alcohol use problem, physical activity, total protein intake, diabetes mellitus, hypertension, dyslipidemia, cardiovascular disease, and metabolic syndrome. The analyses were stratified according to three pre-defined age groups (19-39, $40-59$, and $\geq 60$ years) in all three models. A multivariable logistic regression model was used the enter method, to determine whether serum hs-CRP was independently associated with low HGS. All statistical tests were two-tailed; statistical significance was defined as $p<$ 0.05. All statistical analyses were performed using PASW Statistics, version 18 (IBM Co., Armonk, NY, USA).

\section{RESULTS}

\section{Sample Characteristics}

The sample comprised 9,402 participants; of these, 2,864 were aged $19-39$ years, 3,685 were aged $40-59$ years, and 2,853 were aged $\geq 60$ years. The general characteristics of the study participants according to age group are shown in Table 1. In total, 20.6\%, 14.4\%, and 12.8\% of participants aged $19-39$ years, $40-59$ years, and $\geq$
60 years, respectively, had depression. Females showed significantly higher prevalence of depression than males (19-39 years, $26.4 \%$ vs. $13.7 \%, p<0.001 ; 40-59$ years, $16.9 \%$ vs. $11.2 \%, p<0.001 ; \geq 60$ years, $15.8 \%$ vs. $9.47 \%, p<0.001)$. In the younger age group $(19-39$ years), depression was significantly associated with low income, alcohol use problems, low protein intake, hypertension, and dyslipidemia. In the middle age group (4059 years), participants with depression had significantly lower income, lower physical activity, lower protein intake, and lower BMI. In the older age group ( $\geq 60$ years), depression was significantly associated with low income, low activity, low protein intake, diabetes, and dyslipidemia.

\section{Depression and Low HGS}

In all age groups, participants with depression tended to have lower HGS $(19-39$ years, 29.8 [SD = 10.8] vs. 33.7 [SD $=10.8$ ] kg, $p<0.001 ; 40-59$ years, 29.9 [SD = $10.1]$ vs. $32.4[\mathrm{SD}=10.2] \mathrm{kg}, p<0.001 ; \geq 60$ years, $24.6[\mathrm{SD}=8.9]$ vs. $27.6[\mathrm{SD}=9.2] \mathrm{kg}, p<0.001$ ) (Table 1). Moreover, rates of low HGS were significantly higher in participants with depression than in participants without depression $(19-39$ years, $6.3 \%$ vs. $4.0 \%, p=0.025$ $40-59$ years, $6.0 \%$ vs. $3.9 \%, p=0.034 ; \geq 60$ years, $24.9 \%$ vs. $17.0 \%, p<0.001$ ) (Fig. 2).

In older adults ( $\geq 60$ years), serum hs-CRP levels were significantly higher in individuals with depression than in

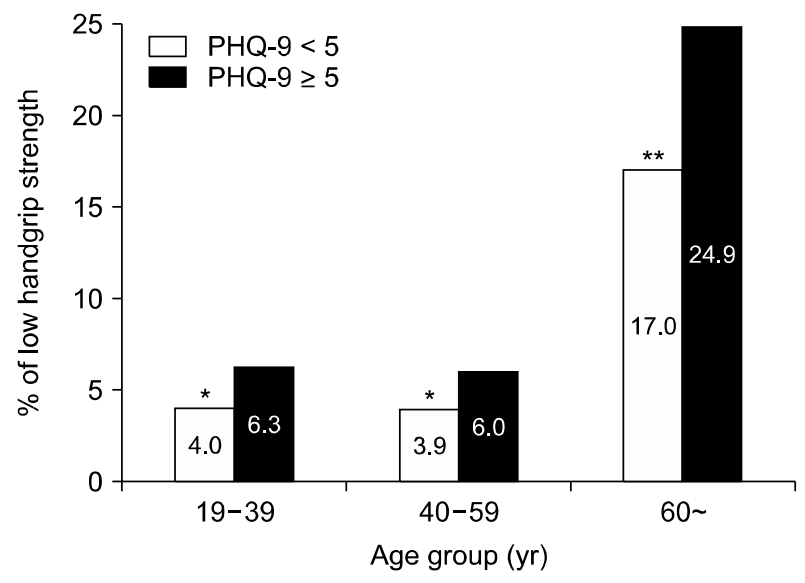

Fig. 2. Age-stratified proportion of adults with low handgrip strength, stratified according to depression status, in KNHANES 2016 and 2018 $(\mathrm{n}=9,402)$.

KNHANES, Korea National Health and Nutrition Examination Survey; PHQ-9, Patient Health Questionnaire-9. ${ }^{*} p$ value $<0.05 ;{ }^{* *} p$ value $<0.001$ 


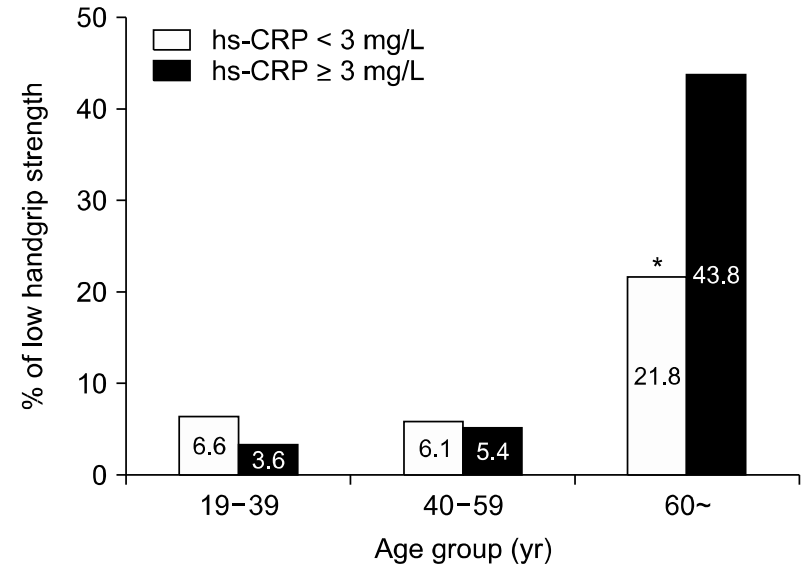

Fig. 3. Age-stratified proportion of adults with depression (PHQ-9 $\geq$ 5) who exhibited low handgrip strength, stratified according to the serum level of high-sensitivity C-reactive protein $(n=1,484)$. hs-CRP, high sensitivity C-reactive protein; PHQ-9, Patient Health Questionnaire-9.

$* p$ value $<0.01$ individuals without depression (1.6 [SD = 2.8] vs. $1.3[\mathrm{SD}=$ 2.2] $\mathrm{ng} / \mathrm{ml}$, respectively). Among older adults with depression, $14.5 \%(n=53)$ had high hs-CRP levels $(\geq 3.0$ $\mathrm{mg} / \mathrm{L})$, compared with $9.3 \%(\mathrm{n}=231)$ of older adults without depression $(p=0.003)$. Conversely, there were no significant associations between serum hs-CRP level and depression in younger and middle-aged adults (Table 1).

\section{Association between Low HGS and Serum hs-CRP Levels in Adults with Depression}

In older adults ( $\geq 60$ years) with depression, $43.8 \%$ of those with hs-CRP levels $\geq 3.0 \mathrm{mg} / \mathrm{L}$ had low HGS, compared to $21.8 \%$ of those with hs-CRP levels $<3.0 \mathrm{mg} / \mathrm{L}(p=$ 0.002). However, among younger and middle-aged adults with depression, the rate of low HGS did not differ according to CRP level (Fig. 3).

Multivariate analysis revealed that, after adjustments for potentially confounding factors, high hs-CRP was independently associated with lower HGS $(B=-2.25$;

Table 2. Multivariate linear regression analysis for handgrip strength in adults with depression, stratified according to the serum hs-CRP level (PHQ-9 $\geq 5, \mathrm{n}=1,484)$

\begin{tabular}{|c|c|c|c|c|c|c|c|c|c|}
\hline & \multicolumn{3}{|c|}{ Age $20-39$ years $(n=589)$} & \multicolumn{3}{|c|}{ Age $40-59$ years $(n=530)$} & \multicolumn{3}{|c|}{ Age $\geq 60$ years $(n=365)$} \\
\hline & $\begin{array}{l}\text { hs-CRP, } \\
<3.0 \mathrm{mg} / \mathrm{L}\end{array}$ & $\begin{array}{l}\text { hs-CRP, } \\
\geq 3.0 \mathrm{mg} / \mathrm{L}\end{array}$ & $p$ value & $\begin{array}{l}\text { hs-CRP, } \\
<3.0 \mathrm{mg} / \mathrm{L}\end{array}$ & $\begin{array}{l}\text { hs-CRP, } \\
\geq 3.0 \mathrm{mg} / \mathrm{L}\end{array}$ & $p$ value & $\begin{array}{l}\text { hs-CRP, } \\
<3.0 \mathrm{mg} / \mathrm{L}\end{array}$ & $\begin{array}{l}\text { hs-CRP, } \\
\geq 3.0 \mathrm{mg} / \mathrm{L}\end{array}$ & $p$ value \\
\hline Model 1 & Reference & $\begin{array}{c}-0.19 \\
(-1.87 \text { to } 1.49)\end{array}$ & 0.826 & Reference & $\begin{array}{c}0.63 \\
(-1.28 \text { to } 2.54)\end{array}$ & 0.517 & Reference & $\begin{array}{c}-2.49 \\
(-3.9 \text { to }-1.0)\end{array}$ & 0.001 \\
\hline Model 2 & Reference & $\begin{array}{c}-0.77 \\
(-1.58 \text { to } 0.06)\end{array}$ & 0.070 & Reference & $\begin{array}{c}0.02 \\
(-0.69 \text { to } 0.73)\end{array}$ & 0.957 & Reference & $\begin{array}{c}-1.42 \\
(-2.10 \text { to }-0.74)\end{array}$ & $<0.001$ \\
\hline Model 3 & Reference & $\begin{array}{c}-0.23 \\
(-2.88 \text { to } 1.73)\end{array}$ & 0.818 & Reference & $\begin{array}{c}-0.15 \\
(-2.30 \text { to } 2.01)\end{array}$ & 0.895 & Reference & $\begin{array}{c}-2.25 \\
(-4.49 \text { to }-0.02)\end{array}$ & 0.048 \\
\hline
\end{tabular}

Values are presented as beta coefficients (95\% confidence interval).

Model 1: adjusted for sex and age (per year); Model 2: Model $1+$ adjustment for income (quartile) and body mass index $\left(<18,18-25, \geq 25 \mathrm{~kg} / \mathrm{m}^{2}\right)$; Model 3: Model $2+$ adjustment for smoking, alcohol use problems, physical activity (low, moderate, high), total protein intake (g/d), hypertension, diabetes, dyslipidemia, metabolic syndrome, and cardiovascular disease.

hs-CRP, high sensitivity C-reactive protein; PHQ-9, Patient Health Questionnaire-9.

Table 3. Logistic regression analysis of the relationship between low handgrip strength and high-sensitivity C-reactive protein level in adults with depression (PHQ-9 $\geq 5, \mathrm{n}=1,484$ )

\begin{tabular}{|c|c|c|c|c|c|c|}
\hline \multirow[b]{2}{*}{ hs-CRP } & \multicolumn{2}{|c|}{ Age $20-39$ years $(n=589)$} & \multicolumn{2}{|c|}{ Age $40-59$ years $(n=530)$} & \multicolumn{2}{|c|}{ Age $\geq 60$ years $(n=365)$} \\
\hline & $\begin{array}{c}\text { Crude OR } \\
(95 \% \mathrm{Cl})\end{array}$ & $\begin{array}{l}\text { Adjusted } \mathrm{OR}^{\mathrm{a}} \\
\quad(95 \% \mathrm{Cl})\end{array}$ & $\begin{array}{c}\text { Crude OR } \\
(95 \% \mathrm{Cl})\end{array}$ & $\begin{array}{c}\text { Adjusted } \mathrm{OR}^{\mathrm{a}} \\
(95 \% \mathrm{Cl})\end{array}$ & $\begin{array}{c}\text { Crude OR } \\
(95 \% \mathrm{Cl})\end{array}$ & $\begin{array}{c}\text { Adjusted } \mathrm{OR}^{\mathrm{a}} \\
(95 \% \mathrm{Cl})\end{array}$ \\
\hline Low $(<3.0 \mathrm{mg} / \mathrm{L})$ & 1 & 1 & 1 & 1 & 1 & 1 \\
\hline High ( $\geq 3.0$ mg/L) & $0.5(0.1-2.3)$ & $0.0(0.0-\propto)$ & $0.9(0.2-3.8)$ & $1.3(0.3-6.6)$ & $2.8(1.5-5.0)^{*}$ & $9.3(1.8-47.9)^{*}$ \\
\hline
\end{tabular}

$\mathrm{Cl}$, confidence interval; OR, odds ratio; hs-CRP, high sensitivity C-reactive protein; PHQ-9, Patient Health Questionnaire-9.

${ }^{a}$ Adjusted for age (per 1 year), sex, low income (quartile 1, low), smoking, alcohol use problems, body mass index $(<18.5,18.5-24.9, \geq 25$ $\mathrm{kg} / \mathrm{m}^{2}$ ), physical activity (low, moderate, high), protein intake, hypertension, diabetes, dyslipidemia, cardiovascular disease, and metabolic syndrome.

${ }^{*} p$ value $<0.05$. 
$95 \%$ confidence interval $=-4.49$ to -0.02 ) in older adults with depression, but not in younger or middle-aged adults with depression (Table 2).

Multiple logistic regression analysis showed this same pattern of associations among age groups (Table 3). In older adults with depression, the high hs-CRP group was 9.3-fold more likely to have low HGS after adjustments for potential confounding factors (adjusted odds ratio $=9.3$, $95 \%$ confidence interval $=1.8-47.9$ ). Conversely, the associations between high hs-CRP level and low HGS in younger and middle-aged adults with depression were not significant, regardless of adjustments for confounding factors (Table 3). Moreover, among adults without depression or with minimal depressive symptoms, no significant associations between high hs-CRP and low HGS were observed in any age group after adjustments for potential confounding factors.

\section{DISCUSSION}

These analyses revealed an association between low HGS and depression in a nationally representative sample of the adult Korean population. An association between serum hs-CRP levels and depression was observed in older adults alone. More importantly, high hs-CRP levels were significantly associated with an elevated risk of low HGS in older adults with depression, but not in younger and middle-aged adults with depression.

Our results are consistent with the findings of two previous cross-sectional studies, which showed significant associations between depression and low HGS $[9,10]$. A large sample study targeting older adults in the USA found that females with moderate to severe depressive symptoms had low HGS; however, no such association was observed in males [11]. Another study found that lower HGS, standardized according to age and sex, was both crosssectionally and longitudinally associated with depressive symptoms [12].

Furthermore, various studies have reported associations between depression and physical functional decline in adults [13,14,30,31]. A recent meta-analysis revealed that more than one-third of older people with physical frailty had depression, and a similar proportion of older people with depression had physical frailty; the odds of each condition were 4-fold greater, compared with controls [32]. These studies provide evidence of a consistent and bidirectional relationship between depression and declining physical function among adults [31,32]. Depressive symptoms might cause this physical functional decline. For instance, depressive symptoms such as poor oral intake, sleep disturbances, and reductions in physical activity can change body composition and metabolism, thereby promoting physical decline $[33,34]$. Furthermore, reduced physical function results in diminished ability to undertake activities of daily living, ultimately leading to social isolation and functional impairment, which enhance the risk of depression [35].

Thus far, epidemiological evidence regarding the association between elevated hs-CRP and depression in general population samples has been inconsistent. Several studies have identified associations between depression and high levels of hs-CRP [36-41], whereas other studies have shown no associations [42-44]. Our analysis, which stratified the study population according to age group, showed that hs-CRP levels were higher among older adults with depression, but not in younger adults. Many previous studies involving older adults have shown an association between high hs-CRP and depression, suggesting that the role of inflammation in depression might be related to age-associated changes in immune system function [40,41]. Notably, our second analysis (based on a sub-sample of adults with depression) also showed a positive association between low HGS and high hs-CRP in older adults with depression, but not in younger or middle-age adults. In older adults with depression, a high hs-CRP level enhanced the odds of low HGS by 9.3-fold. This is presumably because the roles of low-grade inflammation in depression and muscle strength may differ between younger and older adults. The physical functional decline accompanied by late-life depression might most strongly depend on such low-grade inflammation.

Some biological mechanisms may underlie the relationships among low-grade inflammation, physical functional decline, and late-life depression. As noted above, depressive symptoms and declining physical function are generally presumed to exhibit a reciprocal relationship [33-35]. In older age, low-grade inflammation is likely involved in both, comprising the underlying link between depression and physical functional decline [8,17]. Various studies have consistently reported a cross-sectional association between systemic inflammation and reduced muscle strength in older adults [5-8]. In a pro- 
spective study, higher levels of serum interleukin- 6 and CRP were associated with a 2-3-fold greater risk of losing $>40 \%$ of muscle strength over a 3 -year follow-up period [45]. Physical frailty-associated inflammatory processes may underlie the pathway between low muscle strength and depression by activation of the hypothalamus - pituitary-adrenal axis [46,47]. Additionally, depression facilitates the inflammatory response; low-grade inflammation may thus contribute to the development and acceleration of physical functional decline among older people with depression. Furthermore, reduced physical activity and protein intake due to late-life depression may result in further physical functional decline due to sarcopenia, which in itself is associated with low-grade inflammation [48]. Many studies have suggested that aging is associated with immune dysregulation; sustained and prolonged inflammation becomes detrimental to physical and mental health [49-51]. Inflammatory signaling pathways interact with complicated molecular and physiological pathways such as bioactive hormones, nutrition, mitochondria, and genes. With aging, these molecular and physiological changes may contribute to the development of depression and acceleration of physical functional decline in older adults [50,51].

The present study had some limitations. First, the cross-sectional nature of the study design has important implications for the bidirectional relationships among depression, HGS, and hs-CRP levels. Although our findings support the hypothesized link between depression and low HGS, along with the mediating effects of hs-CRP in older adults, the cross-sectional design precludes determination of the causal direction of these associations. Therefore, further studies are necessary to elucidate the effect of low-grade inflammation on the association between depression and physical functional decline; investigating this interaction will require interventional or longitudinal studies. Second, the PHQ-9 [20,21], a self-rated depressive symptom scale, was used to categorize depression in this study, whereas a standardized diagnostic interview would have been more robust. Although the PHQ-9 has been validated as a screening tool for depression, it is not a diagnostic tool. Third, the use of medications (e.g., antidepressants) [52], the effects of recent infections [53], and other major confounding factors for depression, HGS, and inflammation were not considered because the relevant data were unavailable. Despite these limitations, our study included a large sample size, which facilitated the detection of associations between depression and physical functioning; it also included stratification by age group. To the best of our knowledge, this is the first study to evaluate the associations among physical function (measured using HGS) and serum hs-CRP levels in a cohort of adults with depression.

In conclusion, this study revealed a cross-sectional association between depression and low HGS in a community-living Korean adult population. The association between low HGS and high hs-CRP level was more prominent in older adults with depression, compared with younger and middle-aged adults. Further studies are needed to explore the neurobiological mechanisms and clinical consequences of the observed relationships among HGS, low-grade inflammation, and depression.

\section{Conflicts of Interest}

No potential conflict of interest relevant to this article was reported.

\section{Author Contributions}

Conceptualization: Kwi Young Kang, Won-Myong Bahk. Data acquisition: Kwi Young Kang. Formal analysis: Kwi Young Kang, Young-Eun Jung. Supervision: WonMyong Bahk. Writing - original draft: Kwi Young Kang, Young-Eun Jung. Writing - review \& editing: Hwan Jang, Moon-Doo Kim, Young-Eun Jung.

\section{ORCID}

Kwi Young Kang https://orcid.org/0000-0003-0059-119X Young-Eun Jung https://orcid.org/0000-0001-7608-0009 Hwan Jang https://orcid.org/0000-0002-5839-7106 Moon-Doo Kim https://orcid.org/0000-0002-6441-630X Won-Myong Bahk https://orcid.org/0000-0002-0156-2510

\section{REFERENCES}

1. Rantanen T, Guralnik JM, Foley D, Masaki K, Leveille S, Curb JD, et al. Midlife hand grip strength as a predictor of old age disability. JAMA 1999;281:558-560.

2. Giampaoli S, Ferrucci L, Cecchi F, Lo Noce C, Poce A, Dima $\mathrm{F}$, et al. Hand-grip strength predicts incident disability in nondisabled older men. Age Ageing 1999;28:283-288.

3. Wu Y, Wang W, Liu T, Zhang D. Association of grip strength with risk of all-cause mortality, cardiovascular diseases, and cancer in community-dwelling populations: a meta-analysis of prospective cohort studies. J Am Med Dir Assoc 2017;18: 
551.e17-e551.e35.

4. Celis-Morales CA, Welsh P, Lyall DM, Steell L, Petermann F, Anderson J, et al. Associations of grip strength with cardiovascular, respiratory, and cancer outcomes and all cause mortality: prospective cohort study of half a million UK Biobank participants. BMJ 2018;361:k1651.

5. Cesari M, Penninx BW, Pahor M, Lauretani F, Corsi AM, Rhys Williams G, et al. Inflammatory markers and physical performance in older persons: the InCHIANTI study. J Gerontol A Biol Sci Med Sci 2004;59:242-248.

6. Penninx BW, Kritchevsky SB, Newman AB, Nicklas BJ, Simonsick EM, Rubin S, et al. Inflammatory markers and incident mobility limitation in the elderly. I Am Geriatr Soc 2004; 52:1105-1113.

7. Hsu FC, Kritchevsky SB, Liu Y, Kanaya A, Newman AB, Perry $\mathrm{SE}$, et al. Association between inflammatory components and physical function in the health, aging, and body composition study: a principal component analysis approach. J Gerontol A Biol Sci Med Sci 2009;64:581-589.

8. Schaap LA, Pluijm SM, Deeg DJ, Harris TB, Kritchevsky SB, Newman $\mathrm{AB}$, et al. Higher inflammatory marker levels in older persons: associations with 5-year change in muscle mass and muscle strength. J Gerontol A Biol Sci Med Sci 2009;64: 1183-1189.

9. Gale CR, Sayer AA, Cooper C, Dennison EM, Starr JM, Whalley LJ, et al. Factors associated with symptoms of anxiety and depression in five cohorts of community-based older people: the HALCyon (Healthy Ageing across the Life Course) Programme. Psychol Med 2011;41:2057-2073.

10. van Milligen BA, Lamers F, de Hoop GT, Smit JH, Penninx BW. Objective physical functioning in patients with depressive and/or anxiety disorders. J Affect Disord 2011;131:193199.

11. Smith L, White S, Stubbs B, Hu L, Veronese N, Vancampfort D, et al. Depressive symptoms, handgrip strength, and weight status in US older adults. J Affect Disord 2018;238:305-310.

12. Fukumori N, Yamamoto Y, Takegami M, Yamazaki S, Onishi $\mathrm{Y}$, Sekiguchi M, et al. Association between hand-grip strength and depressive symptoms: Locomotive Syndrome and Health Outcomes in Aizu Cohort Study (LOHAS). Age Ageing 2015; 44:592-598.

13. Firth J, Firth JA, Stubbs B, Vancampfort D, Schuch FB, Hallgren $\mathrm{M}$, et al. Association between muscular strength and cognition in people with major depression or bipolar disorder and healthy controls. JAMA Psychiatry 2018;75:740-746.

14. Rijk JM, Roos PR, Deckx L, van den Akker M, Buntinx F. Prognostic value of handgrip strength in people aged 60 years and older: a systematic review and meta-analysis. Geriatr Gerontol Int 2016;16:5-20.

15. Vaughan L, Corbin AL, Goveas JS. Depression and frailty in later life: a systematic review. Clin Interv Aging 2015;10: 1947-1958.

16. Brown PJ, Rutherford BR, Yaffe K, Tandler JM, Ray JL, Pott E, et al. The depressed frail phenotype: the clinical manifestation of increased biological aging. Am J Geriatr Psychiatry 2016;24:1084-1094.

17. Arts MH, Collard RM, Comijs HC, Naudé PJ, Risselada R, Naarding $\mathrm{P}$, et al. Relationship between physical frailty and low-grade inflammation in late-life depression. J Am Geriatr Soc 2015;63:1652-1657.

18. Bolu A, Aydın MS, Akgün A, Coşkun A, Garip B, Öznur T, et al. Serum levels of high sensitivity $C$-reactive protein in drug-nalve first-episode psychosis and acute exacerbation of schizophrenia. Clin Psychopharmacol Neurosci 2019;17: 244-249.

19. Kweon S, Kim Y, Jang MJ, Kim Y, Kim K, Choi S, et al. Data resource profile: the Korea National Health and Nutrition Examination Survey (KNHANES). Int J Epidemiol 2014;43:6977.

20. Kroenke K, Spitzer RL, Williams JB. The PHQ-9: validity of a brief depression severity measure. J Gen Intern Med 2001;16: 606-613.

21. Han C, Jo SA, Kwak JH, Pae CU, Steffens D, Jo I, et al. Validation of the Patient Health Questionnaire-9 Korean version in the elderly population: the Ansan Geriatric study. Compr Psychiatry 2008;49:218-223.

22. Roberts HC, Denison HJ, Martin HJ, Patel HP, Syddall H, Cooper $\mathrm{C}$, et al. A review of the measurement of grip strength in clinical and epidemiological studies: towards a standardised approach. Age Ageing 2011;40:423-429.

23. Chen LK, Liu LK, Woo J, Assantachai P, Auyeung TW, Bahyah KS, et al. Sarcopenia in Asia: consensus report of the Asian Working Group for Sarcopenia. J Am Med Dir Assoc 2014; 15:95-101.

24. Pearson TA, Mensah GA, Alexander RW, Anderson JL, Cannon RO 3rd, Criqui M, et al. Markers of inflammation and cardiovascular disease: application to clinical and public health practice: a statement for healthcare professionals from the Centers for Disease Control and Prevention and the American Heart Association. Circulation 2003;107:499-511.

25. Gordon AJ, Maisto SA, McNeil M, Kraemer KL, Conigliaro RL, Kelley ME, et al. Three questions can detect hazardous drinkers. J Fam Pract 2001;50:313-320.

26. Kurtze N, Rangul V, Hustvedt BE. Reliability and validity of the international physical activity questionnaire in the Nord-Trondelag health study (HUNT) population of men. BMC Med Res Methodol 2008;8:63.

27. IPAQ Research Committee. International physical activity questionnaire [Internet]. International Physical Activity Questionnaire [cited at $2020 \mathrm{Mar}$ 12]. Available from: https://sites. google.com/site/theipaq/scoring-protocol.

28. Rural Development Administration. Food composition table. 7th ed. Suwon:National Rural Resources Development Institute, 2006.

29. Grundy SM, Cleeman JI, Daniels SR, Donato KA, Eckel RH, Franklin BA, et al. Diagnosis and management of the metabol- 
ic syndrome: an American Heart Association/National Heart, Lung, and Blood Institute Scientific Statement. Circulation 2005; 112:2735-2752.

30. Veronese N, Stubbs B, Trevisan C, Bolzetta F, De Rui M, Solmi $\mathrm{M}$, et al. Poor physical performance predicts future onset of depression in elderly people: Progetto Veneto Anziani longitudinal study. Phys Ther 2017;97:659-668.

31. Buigues C, Padilla-Sánchez C, Garrido JF, Navarro-Martínez $\mathrm{R}$, Ruiz-Ros V, Cauli O. The relationship between depression and frailty syndrome: a systematic review. Aging Ment Health 2015; 19:762-772.

32. Soysal P, Veronese N, Thompson T, Kahl KG, Fernandes BS, Prina AM, et al. Relationship between depression and frailty in older adults: a systematic review and meta-analysis. Ageing Res Rev 2017;36:78-87.

33. Penninx BW, Leveille S, Ferrucci L, van Eijk JT, Guralnik JM. Exploring the effect of depression on physical disability: longitudinal evidence from the established populations for epidemiologic studies of the elderly. Am J Public Health 1999; 89:1346-1352.

34. Lenze EJ, Rogers JC, Martire LM, Mulsant BH, Rollman BL, Dew MA, et al. The association of late-life depression and anxiety with physical disability: a review of the literature and prospectus for future research. Am J Geriatr Psychiatry 2001; 9:113-135.

35. Choi $\mathrm{H}$, Irwin MR, Cho HJ. Impact of social isolation on behavioral health in elderly: systematic review. World J Psychiatry 2015;5:432-438.

36. Jung YE, Kang KY. Elevated hs-CRP level is associated with depression in younger adults: results from the Korean National Health and Nutrition Examination Survey (KNHANES 2016). Psychoneuroendocrinology 2019;109:104397.

37. Tabatabaeizadeh SA, Abdizadeh MF, Meshkat Z, Khodashenas $\mathrm{E}$, Darroudi S, Fazeli M, et al. There is an association between serum high-sensitivity C-reactive protein (hs-CRP) concentrations and depression score in adolescent girls. Psychoneuroendocrinology 2018;88:102-104.

38. Ford DE, Erlinger TP. Depression and C-reactive protein in US adults: data from the Third National Health and Nutrition Examination Survey. Arch Intern Med 2004;164:1010-1014.

39. Wium-Andersen MK, Ørsted DD, Nielsen SF, Nordestgaard BG. Elevated C-reactive protein levels, psychological distress, and depression in 73, 131 individuals. JAMA Psychiatry 2013;70:176-184.

40. Song BM, Lee JM, Choi W, Youm Y, Chu SH, Park YR, et al. Association between $C$ reactive protein level and depressive symptoms in an elderly Korean population: Korean Social Life, Health and Aging Project. BMJ Open 2015;5:e006429.

41. Liukkonen T, Silvennoinen-Kassinen S, Jokelainen J, Räsänen
$\mathrm{P}$, Leinonen M, Meyer-Rochow VB, et al. The association between C-reactive protein levels and depression: results from the Northern Finland 1966 birth cohort study. Biol Psychiatry 2006;60:825-830.

42. Chaiton M, O'Loughlin J, Karp I, Lambert M. Depressive symptoms and C-reactive protein are not associated in a population-based sample of adolescents. Int I Behav Med 2010; 17:216-222.

43. de Menezes ST, de Figueiredo RC, Goulart AC, Nunes MA, M Benseñor I, Viana MC, et al. Lack of association between depression and C-reactive protein level in the baseline of Longitudinal Study of Adult Health (ELSA-Brasil). I Affect Disord 2017;208:448-454.

44. Almeida OP, Norman P, Hankey GJ, Jamrozik K, Flicker L. The association between C-reactive protein concentration and depression in later life is due to poor physical health: results from the Health in Men Study (HIMS). Psychol Med 2007;37:1775-1786.

45. Schaap LA, Pluijm SM, Deeg DJ, Visser M. Inflammatory markers and loss of muscle mass (sarcopenia) and strength. Am J Med 2006;119:526.e9- e17.

46. Bremmer MA, Beekman AT, Deeg DJ, Penninx BW, Dik MG, Hack CE, et al. Inflammatory markers in late-life depression: results from a population-based study. J Affect Disord 2008; 106:249-255.

47. Schiepers OJ, Wichers MC, Maes M. Cytokines and major depression. Prog Neuropsychopharmacol Biol Psychiatry 2005;29:201-217.

48. Visser M, Pahor M, Taaffe DR, Goodpaster BH, Simonsick EM, Newman AB, et al. Relationship of interleukin- 6 and tumor necrosis factor-alpha with muscle mass and muscle strength in elderly men and women: the Health ABC Study. J Gerontol A Biol Sci Med Sci 2002;57:M326-M332.

49. Alexopoulos GS, Morimoto SS. The inflammation hypothesis in geriatric depression. Int J Geriatr Psychiatry 2011;26:11091118.

50. Fried LP, Xue QL, Cappola AR, Ferrucci L, Chaves P, Varadhan $\mathrm{R}$, et al. Nonlinear multisystem physiological dysregulation associated with frailty in older women: implications for etiology and treatment. I Gerontol A Biol SCi Med SCi 2009;64:1049-1057.

51. Wilson D, Jackson T, Sapey E, Lord JM. Frailty and sarcopenia: the potential role of an aged immune system. Ageing Res Rev 2017;36:1-10.

52. Castanon N, Leonard BE, Neveu PJ, Yirmiya R. Effects of antidepressants on cytokine production and actions. Brain Behav Immun 2002;16:569-574.

53. Sproston NR, Ashworth JJ. Role of C-reactive protein at sites of inflammation and infection. Front Immunol 2018;9:754. 